\title{
Genetic drift and the maintenance of the style length polymorphism in tristylous populations of Eichhornia paniculata (Pontederiaceae)
}

\author{
BRIAN C. HUSBAND* \& SPENCER C. H. BARRETT \\ Department of Botany, University of Toronto, Toronto, Ontario, Canada M5S $3 B 2$
}

\begin{abstract}
We investigated whether stochastic processes influence the frequency of mating types within populations of tristylous Eichhornia paniculata in northeastern Brazil. The importance of genetic drift as a result of small populations was evaluated using survey data on spatial and temporal variation in style morph frequencies in natural populations. The patterns expected when morph variation is due entirely to stochastic forces in finite populations were determined by computer simulation of tristylous populations, for various sampling schemes. Surveys of a total of 167 populations, censused during 1982-1989, indicated that morph structure was negatively correlated with population size. Populations with three style morphs were significantly larger than those containing two or one morph, suggesting that evolutionary processes in small populations may account for morph loss. In 88 populations surveyed for either 2 or 3 consecutive years, 33 per cent showed significant changes in morph frequency. There were no consistent patterns in the direction of morph frequency change and the magnitude of change was largest in small populations $(N<50)$. Among the 12 trimorphic populations that lost morphs during the survey period, the $L, M$ and $S$ morphs were lost 2, 6 and 11 times respectively, a pattern consistent with stochastic morph loss under the two-locus inheritance pattern for tristyly. Simulation results indicated that the observed proportion of populations with significant morph frequency change and the magnitude of this change could be accounted for by random processes alone. Collectively, these findings are consistent with the hypothesis that genetic drift plays an important role in influencing morph frequencies in populations of $E$. paniculata.
\end{abstract}

Keywords: computer simulations, Eichhornia paniculata, genetic drift, temporal variation, tristyly.

\section{Introduction}

Small populations are an important feature of many plants and animals that colonize ephemeral and patchily distributed habitats. Low numbers of individuals may result when suitable habitats are restricted in size (Moran \& Hopper, 1983; Hanski, 1985; McClenaghan \& Beauchamp, 1986; Billington, 1991), populations are geographically isolated with low immigration (Harrison et al., 1988) or when populations are maintained in the early stages of establishment due to fre-

*Present address: Department of Botany, University of Washington, Seattle, Washington 98195, U.S.A. quent extinction and recolonization (Olivieri et al., 1990). These demographic processes have important genetic consequences because inbreeding and stochastic loss of variation is most likely in small populations (Lande \& Barrowclough, 1987; Barrett \& Kohn, 1991). While the theoretical consequences of genetic drift are well understood, particularly for neutral genes (Wright, 1931; 1951), there have been few empirical studies on its role in the maintenance of conspicuous polymorphisms in natural populations, particularly when they may be of adaptive significance (Epling \& Dobzhansky, 1942; Wright, 1943; Oxford \& Shaw, 1986; Eckert \& Barrett, 1992).

Eichhornia paniculata (Pontederiaceae) is a selfcompatible, annual aquatic that occurs in seasonal 
pools and wet ditches in northeastern Brazil and the Caribbean islands of Jamaica and Cuba (Barrett, 1985a). In Brazil, these habitats are patchily distributed, depending on the location and duration of rainfall in any particular year. As a result, populations usually contain a small number of individuals. Surveys in northeastern Brazil have revealed that, within a given year, about 50 per cent of populations contain less than 100 individuals, and size fluctuates widely in time (Husband, 1992). Moreover, genetic studies indicate that effective population size $\left(N_{\mathrm{e}}\right)$ is about 10 per cent of these values, primarily because of annual fluctuations in number and large variances in reproductive capacity among individuals (Husband \& Barrett, 1992a). Because of this population biology, it has been suggested that stochastic processes in small populations of $E$. paniculata may have a significant effect on the maintenance of its tristylous breeding system, resulting in unequal style morph frequencies and the loss of morphs from populations (Barrett, 1985b; Barrett et al., 1989).

Populations of $E$. paniculata usually contain three mating types or morphs, distinguishable primarily by their style length (long-, mid- and short-styled morphs; hereafter L, M, S morphs). In theory, the style morphs in tristylous species are maintained near equal frequencies in large populations by frequency-dependent selection, a consequence of strong disassortative mating (Fisher, 1944; Heuch, 1979; Barrett et al., 1987). However, surveys in natural populations of $E$. paniculata indicate that morph frequencies are often unequal and that in a significant number of populations (29 per cent) either one or two morphs are absent (Barrett et al., 1989). Simulation studies of the maintenance or tristyly in finite populations have indicated that morph loss due to genetic drift can occur in populations with less than 30-40 individuals and that the $S$ morph is most commonly lost (Heuch, 1980).

We investigated both spatial and temporal variation in morph frequencies in natural populations of Eichhornia paniculata in northeastern Brazil to determine whether genetic drift is likely to influence the maintenance of tristyly in small populations. First, we established whether there was a statistically significant inverse relationship between morph structure and size among 167 populations. The underlying cause of such a relationship and specifically the role of stochastic processes was then evaluated by examining the magnitude and direction of temporal change in morph frequencies through surveys of a large sample of populations for 2-3 consecutive years. Empirical data from population surveys were then compared with expectations based on the effects of drift, developed using computer simulations.

\section{Materials and methods}

\section{Population survey}

We sampled morph frequencies and estimated population size in 167 populations of Eichhornia paniculata in northeastern Brazil. Populations were sampled along most major roadways in May and June during 1982, 1987,1988 and 1989 . In each survey, we attempted to sample virtually all populations encountered, including those previously examined. As most habitats are ephemeral, many populations did not persist over the 7 -year sampling period. Of the 167 populations, 76 populations were censused over a 1-year interval (i.e. two consecutive years), including some populations surveyed in two different intervals (1987-1988, 1988-1989), 32 populations were sampled over a 2-year interval (1987-1989), four populations over 5and 6-year intervals and three populations sampled over a 7-year interval. Populations sampled over greater than a 2-year interval were not used in temporal analyses because sample sizes were too small. The average morph frequencies surveyed in 1982 and 1987 have been reported previously by Barrett (1985b) and Barrett et al. (1989), respectively.

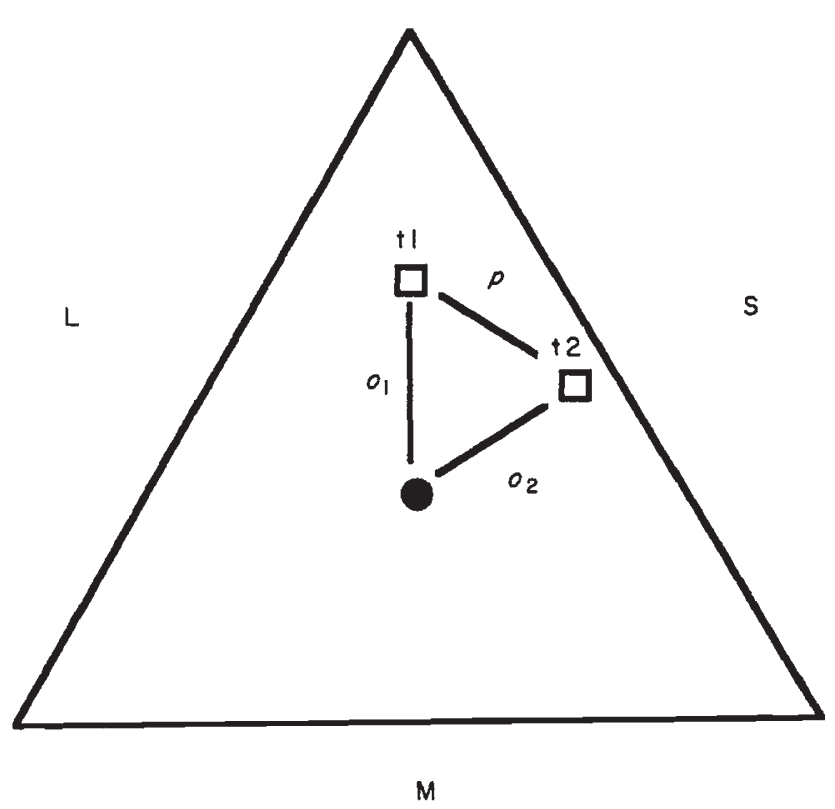

Fig. 1 Triangle plot on which indices of morph diversity and morph diversity change are calculated for tristylous populations. The solid dot represents the point of equal morph frequencies (isoplethy). Morph diversity is measured as the Euclidean distance between a population, plotted on the triangle, and isoplethy ( $O$ index $)$. Change in morph diversity in time is the distance between a population plotted at two different census times ( $P$ index). See methods for details. 
Population size. The number of reproducing individuals was estimated for all populations surveyed. Each estimate was the average of at least two independent estimates. In populations less than 250 individuals, size was determined by complete census. In populations sampled over more than 1 year, population size was based on the harmonic mean (Wright, 1938). The mean size of populations containing one, two and three morphs was reported using both the geometric and arithmetic mean. Because of the skewed distribution of population size, the geometric mean best approximated the 50th percentile. To examine associations between population size and morph structure, populations were grouped into seven size classes: 1-25, 26-50, 51-100, $101-200,201-500,501-1000$, and greater than 1000 .

Style morph frequencies. We estimated the frequency of $\mathrm{L}, \mathrm{M}$ and $\mathrm{S}$ morphs in each population. In large populations, the frequency of style morphs was estimated from at least 100 randomly sampled inflorescences. In small populations $(N \leq 250)$, a complete census of individuals was taken. As E. paniculata grows primarily as an annual in Brazil, with no clonal growth, there was no difficulty in distinguishing genets.

Morph frequencies within populations were reported as a single measure of diversity described by the position of a population on a triangular plot (Fig. 1). The triangular plot has been used previously by Morgan \& Barrett (1988) to illustrate morph frequencies in populations of tristylous Pontederia cordata. Each side of the triangle represents a different style morph and the distance a population is plotted from a given side is in direct proportion to the frequency of that morph within a population. Here, morph diversity was described as the Euclidean distance between a given population and the point of equal frequency (isoplethy) on the triangular plot (Fig. 1; $O$ Index). To be consistent with previous measures of morph diversity (Barrett et al., 1989), this distance was normalized by the maximum distance possible (0.6667) such that the diversity of monomorphic populations was 0 , and diversity in populations with three morphs at equal frequency was 1 .

Temporal changes in morph diversity, relative to isoplethy, were measured as the difference between indices of morph diversity in two different sampling periods $\left(O_{2}-O_{1}\right)$. A positive value indicates that morph frequencies have shifted away from isoplethy; a negative, towards isoplethy. Alternatively, absolute changes in morph diversity, irrespective of the theoretical expectation of $1: 1: 1$, were calculated as the Euclidean distance between the two samples of the same population ( $P$ Index). The latter measure was used when examining changes in morph diversity as a function of population size. As the $\mathrm{S}$ morph is most commonly absent in dimorphic populations of $E$. paniculata, particular attention was also given to temporal changes in frequency of the $S$ morph.

For each population sampled for over 1- or 2-year intervals, a chi-square test of homogeneity was calculated to test the hypothesis that morph frequencies did not change with time. The percentage of populations with a significant change in morph frequency was compared to expectations based on drift alone, calculated using computer simulations (see below). Chi-square tests were also used to test whether changes in morph frequency were random in direction and whether they were a function of initial morph frequencies. In addition, the null hypothesis that variation in morph frequency is caused by stochastic processes was tested by examining the magnitude and direction of temporal changes in morph diversity as a function of population size using the Kruskal-Wallis test. The magnitude of morph frequency change observed, calculated for five size classes $(1-25,26-50,51-150,151-500$ and 501-1500), was compared to theoretical expectations generated from computer simulations that incorporated the same sampling schemes.

\section{Genetic models of temporal variation in morph frequency}

Monte Carlo simulations were used to determine the changes in morph frequency expected from stochastic processes (genetic drift and sampling error) in small tristylous populations. Specifically, we determined the percentage of populations that would exhibit statistically significant changes in morph frequency during a 1 -year interval. In addition, we determined the average change in morph frequency in populations of different size, corresponding to the five size classes used to examine temporal variation in natural populations (1-25, 26-50, 51-150, 151-500, 501-1500). Simulation results were based on genetic estimates of effective population size from an earlier study (Husband \& Barrett, 1992a) and sample sizes used in field surveys of E. paniculata.

Populations of size $N$ were initially founded by genotypes chosen randomly from an infinite tristylous population at equilibrium. Equilibrium frequencies for the nine possible style morph genotypes were reported by Heuch \& Lie (1985). Each year the genotypes were replaced by $N$ offspring, each generated by randomly sampling gametes from a maternal and a paternal parent. Maternal parents were selected at random from the population. We used a mating algorithm similar to that used by Barrett et al. (1989) and Eckert \& Barrett 
(1992) to select the paternal parent, where a proportion $s$ of the offspring are derived from self-fertilization and the remainder, $1-s$, from outcrossing. Of the outcrossed progeny, a proportion $d$ result from disassortative mating (between morphs) and a proportion $r$ $(r=1-d)$ from random outcrossing. In this study, average estimates of these mating parameters from natural populations (see Barrett et al., 1987; Barrett \& Husband, 1990) were used in the simulations $(s=0.15$, $d=0.95, r=0.05$ ).

Changes in morph frequency were monitored in populations that were trimorphic in the first sampling period. We determined the change in morph frequencies by sampling genotypes from the mating population in generations three and four. Populations were sampled in these generations to increase the number of populations with all three morphs. Sampling later required many more replicate populations and had no noticeable effect on the magnitude of morph frequency change. To simulate the sampling protocol used in field studies, the number of genotypes sampled depended on population size but did not exceed 100 in populations larger than 250 .

To determine the percentage of significant changes in morph frequency, simulated populations were made equivalent to the average effective population size for $E$. paniculata populations involved in this study $\left(N_{\mathrm{e}}=15\right)$. This value was based on the evidence that $N_{\mathrm{e}}$ is approximately 16 per cent of the harmonic mean of population size $(N)$, as determined in previous studies of effective population size (Husband \& Barrett, 1992a). Because these estimates are made retrospectively using genetic methods, $N_{\mathrm{e}}$ is the cumulative effect of all potential demographic characteristics that could affect the representation of genes in populations of $E$. paniculata, including fluctuations in population size, variance in reproductive output and non-random mating. Simulations were replicated 500 times and, in accordance with the median sample size in natural populations, morph frequencies were generated from a random sample of 100 . After each simulation, the significance of temporal changes in morph frequency was tested using a $3 \times 2$ contingency chi-square test with 2 d.f. Additional símulations were conducted using various effective population sizes and sample sizes to determine the sensitivity of morph frequency changes to sampling scheme.

To examine the magnitude of morph frequency change in populations of different size, we conducted two sets of simulations. Population sizes used in the first set of simulations corresponded to the midpoint of the five size classes used in field studies $(N=13,37,100$, $350,1000)$. However, because effective population size is much smaller than the harmonic mean for each population, we also ran simulations in which each population size was adjusted $\left(N_{\mathrm{e}}=N / 6.3\right)$ to approximate $n_{\mathrm{e}}$ (adjusted $N=3,6,16,55,159$ ). All genotypes were sampled in simulated populations except if $N>250$, in which case 100 genotypes were sampled without replacement. The mean change in morph frequency ( $P$ radius) and its standard deviation was calculated from 500 replicate simulations for each population size-class. Each simulation involved the same number of populations as were observed in the field. The significance of the deviation between observed and expected mean change in morph frequency, expressed as a standard normal deviate, was evaluated using a $t$ distribution.

\section{Results}

\section{Population size and variation in morph structure}

Population sizes among the 167 populations of $E$. paniculata surveyed in northeastern Brazil ranged from 1 to 8,000 individuals; the arithmetic mean was 416 (Table 1). Most of the populations were small, with more than 50 per cent having less than 100 individuals. The geometric mean of population size was 93.4. As each population estimate is the harmonic mean of all

Table 1 Mean and range of population size for trimorphic, dimorphic and monomorphic populations of Eichhornia paniculata from northeastern Brazil. Differences in size among morph-structure categories was significant in a Kruskal-Wallis three group test $(H=31.9, P<0.0001)$

\begin{tabular}{llccc}
\hline Variable & Trimorphic & Dimorphic & Monomorphic & Overall \\
\hline$n$ & 118 & 42 & 7 & 167 \\
Arithmetic mean & 516.6 & 202.1 & 19.2 & 416.6 \\
Geometric mean & 146.3 & 38.2 & 10.2 & 93.4 \\
Range & $2-8000$ & $3-4000$ & $1-4000$ & $1-8000$ \\
\hline
\end{tabular}


Fig. 2 Percentage of trimorphic $(\square)$ and non-trimorphic ( $\square$ ) populations of E. paniculata from northeastern Brazil that occur within seven population size classes. The size classes $(1-25,26-50$, 51-100, 101-200, 201-500, 501-1000, 1001-7000) were chosen to maximize the sample sizes within classes. A $\chi^{2} 2 \times 6$ contingency analysis was conducted to test the null hypothesis that morph structure and population size were independent (see Results).

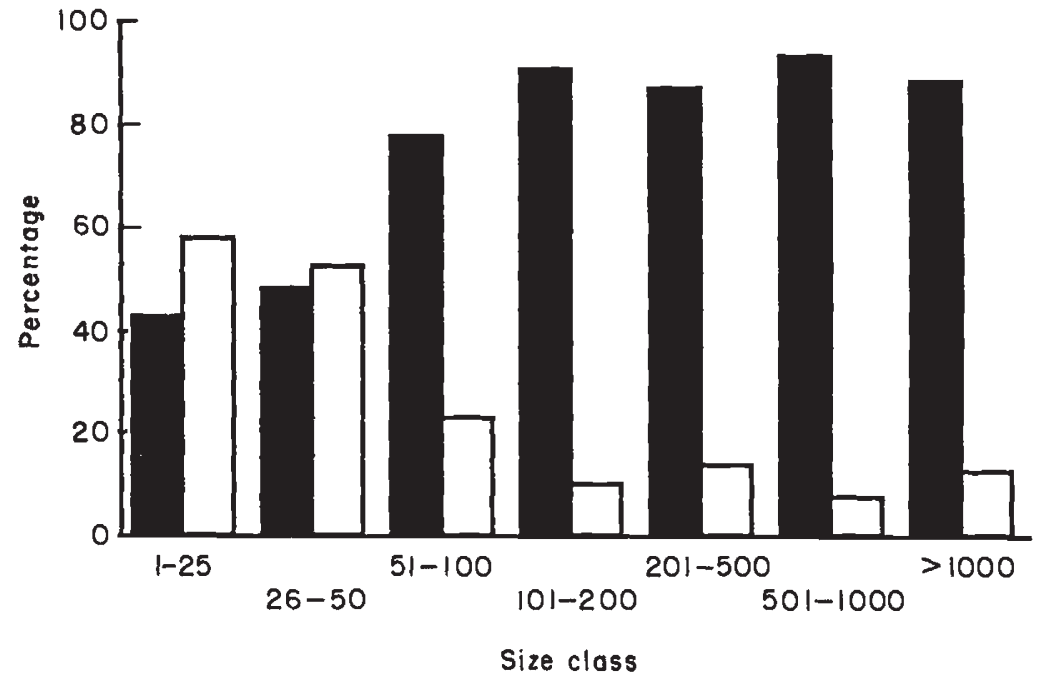

Table 2 Population morph structure in surveys of Eichhornia paniculata from northeastern Brazil conducted in 1982, 1987, 1988 and 1989. The percentage of populations in each morph structure category is presented. The proportion of the $n$ populations sampled each year that was sampled in previous years is listed in brackets

\begin{tabular}{|c|c|c|c|c|c|c|c|c|}
\hline \multirow[b]{2}{*}{ Year } & \multirow[b]{2}{*}{$n$} & \multirow{2}{*}{$\begin{array}{l}\text { Trimorphic } \\
\text { LMS }\end{array}$} & \multicolumn{3}{|c|}{ Dimorphic } & \multicolumn{3}{|c|}{ Monomorphic } \\
\hline & & & $\mathrm{LM}$ & LS & MS & L & M & $S$ \\
\hline 1982 & $30(0)$ & 70.0 & 20.0 & - & - & - & 10.0 & - \\
\hline 1987 & $58(6.9)$ & 69.0 & 25.8 & - & - & - & 5.2 & - \\
\hline 1988 & $85(44.7)$ & 77.6 & 18.9 & - & - & - & 3.5 & - \\
\hline 1989 & $79(54.4)$ & 55.7 & 20.3 & 6.3 & 2.5 & 6.3 & 8.9 & - \\
\hline
\end{tabular}

yearly censuses and $N_{\mathrm{e}}$ is about 6.3 times less than population size estimates, based on the harmonic mean (Husband \& Barrett, 1992a), the mean genetically effective population size is roughly 15 .

Of the 167 populations sampled during 1982-1989, 118 were trimorphic, 42 were dimorphic and seven were monomorphic. The mean and range in population size were largest in trimorphic populations and smallest in monomorphic populations (Table 1). The difference in mean size was significant in a Kruskal-Wallis three-group test $\left(H_{\mathrm{adj}}=31.9, P<0.0001\right)$. Populations of different size had markedly different morph structures. There was a significant association between population size-class and the proportion of populations with all three style morphs $\left(\chi^{2}=35.2, P<0.001\right.$, d.f. $=6$; Fig. 2). Fifty-six per cent of all populations containing less than 50 individuals were dimorphic or monomorphic; 12 per cent of populations larger than 1000 were non-trimorphic.

\section{Temporal variation in morph frequencies}

The distribution of style morphs among populations in northeastern Brazil was consistent among the four annual population surveys (Table 2). Between 56 and 78 per cent of all populations were trimorphic and 19-29 per cent were dimorphic in any given survey. With the exception of the 1989 survery, dimorphic populations consisted solely of $L$ and $M$ morphs. In 1989 , dimorphic populations with $\mathrm{L}$ and $\mathrm{S}$ morphs and $\mathrm{M}$ and $\mathrm{S}$ morphs were found in southern regions of northeastern Brazil not previously surveyed. In the first three surveys, monomorphic populations were fixed for the $\mathrm{M}$ morph. The loss of morphs from some previously trimorphic and dimorphic populations led to the incidence of some monomorphic $L$ populations in the 1989 sample. The representation of trimorphic, dimorphic and monomorphic populations in $E$. paniculata was uniform among the four surveys based 
Table 3 Summary of changes in the number of morphs in populations of Eichhornia paniculata from northeastern Brazil that were sampled over 1- and 2-year intervals

\begin{tabular}{|c|c|c|c|c|c|c|}
\hline & \multirow[b]{2}{*}{$n$} & \multicolumn{5}{|c|}{ Change in morph number } \\
\hline & & -2 & -1 & No change & +1 & +2 \\
\hline \multicolumn{7}{|l|}{ One-year interval } \\
\hline $1987-1988$ & 36 & 0 & 2 & 33 & 1 & 0 \\
\hline $1988-1989$ & 40 & 6 & 7 & 27 & 0 & 0 \\
\hline Total & 76 & 6 & 9 & 60 & 1 & 0 \\
\hline \multicolumn{7}{|l|}{ Two-year interval } \\
\hline $1987-1989$ & 32 & 4 & 5 & 23 & 0 & 0 \\
\hline
\end{tabular}

on a chi-square test of homogeneity $\left(\chi^{2}=5.15, P>0.1\right.$, d.f. $=6$ ).

Changes in morph number. Populations surveyed for 2-3 years exhibited considerable fluctuations in morph number. Nine (28 per cent) of the 32 populations observed over 3 years lost one or two morphs. Of the 76 populations sampled for 2 consecutive years, 15 (19.6 per cent) lost one or two morphs, while only one (1.3 per cent) gained a morph (Table 3 ). Twelve of the populations that lost at least one morph were initially trimorphic. After a single generation, 11 of these had lost the S morph, six had lost the $\mathrm{M}$ morph and 2, the $\mathrm{L}$ morph. The remaining non-trimorphic populations $(n=3)$, which initially contained the $\mathrm{L}$ and M morphs, all lost the $\mathrm{L}$ morph.

Significance levels of changes in morph frequency. Trimorphic populations surveyed over 2-3 years exhibited marked changes in morph frequency. Thirty-two populations were censused over three consecutive years; 21 of these were trimorphic. Based on chi-square tests of homogeneity, 33.3 per cent (7) showed significant changes in morph frequency. Of the 76 populations monitored for two consecutive years, 59 were initially trimorphic and 32.2 per cent (19) of these populations showed significant changes in morph frequency.

Computer simulations were used to determine the percentage of significant chi-square tests expected from drift alone in finite populations sampled for two consecutive years. Simulations showed that the percentage of populations with significant changes in morph frequency increased as the sample size $(S)$ to $N_{\mathrm{e}}$ ratio increased. When the population sample was less than $N_{\mathrm{e}}$, none of the tests were significant; however, if the sample size was five times greater than $N_{\mathrm{e}}$, about 40 per cent of all tests were significant. For simulated populations with an average effective population size
Table 4 Percentage of simulated tristylous populations sampled in 2 consecutive years with significant changes in style morph frequency. Significance levels were based on chisquare tests of homogeneity on 500 replicate populations. Morph frequencies were determined from a sample $(S)$ of individuals. Percentages are shown for various combinations of effective population size $\left(N_{\mathrm{e}}\right)$ and sample size $(S)$

\begin{tabular}{|c|c|c|c|c|c|}
\hline \multirow[b]{2}{*}{$N_{\mathrm{e}}$} & \multicolumn{5}{|c|}{$S / N_{\mathrm{e}}$} \\
\hline & 0.5 & 1 & 2 & 5 & 6.3 \\
\hline 15 & 0.0 & 2.1 & 16.7 & 40.8 & 39.6 \\
\hline 25 & 0.0 & 2.0 & 14.0 & 44.0 & 48.0 \\
\hline 50 & 0.0 & 0.0 & 8.0 & 46.0 & 54.0 \\
\hline 100 & 0.0 & 0.0 & 16.0 & 28.0 & 58.0 \\
\hline 200 & 0.0 & 0.0 & 10.0 & 36.0 & 54.0 \\
\hline
\end{tabular}

of 15 and mean sample size of 100 individuals, as in the empirical sample of E. paniculata, 39 per cent of populations exhibited significant changes in morph frequency (Table 4).

Magnitude of morph frequency change. Changes in morph frequency observed in trimorphic populations, and reported here as temporal variation in morph diversity $(O$ index $)$, resulted in shifts toward and away from equal frequencies. In 59 trimorphic populations censused for 2 consecutive years, there were significantly more changes toward uneven morph frequencies than toward equal morph frequencies ( 37 away: 22 toward equality, $\chi^{2}=3.6$, d.f. $=1, P<0.05$ ) (Fig. 3a). Changes in morph diversity away from equal morph frequencies were also more likely in populations surveyed over a 3-year period (15 away: six toward equality, $\chi^{2}=3.8$, d.f. $\left.=1, P<0.05\right)$. However, when only populations with significant changes in morph frequency were examined there was no difference in the number of shifts toward versus away from equality, for censuses over a 1-year interval (13 away: eight toward $\chi^{2}=1.19$, d.f. $=1, P>0.25$ ) or 2-year interval (four away: three toward; Binomial expansion, $P=1$ ). Similarly, there was no consistent direction of change in the frequency of the $S$ morph (Fig. 3b). That is, the $S$ morph increased and decreased with equal frequency when observed over a single year $\left(\chi^{2}=0.153\right.$, d.f. $=1$, $P>0.5, n=59)$ as well as over a 2-year interval $\left(\chi^{2}=0.81, P>0.25, n=29\right)$. In addition, the direction that either morph diversity or the $S$ morph changed, during 2 consecutive years, was not contingent upon initial frequency (Morph diversity: $\chi^{2}=3.59$, d.f. $=2$, $P>0.10 ;$ S morph frequency: $\chi^{2}=0.199$, d.f. $=2$, $P>0.75)$. The same pattern was revealed in analyses of only those populations with significant morph frequency changes. 

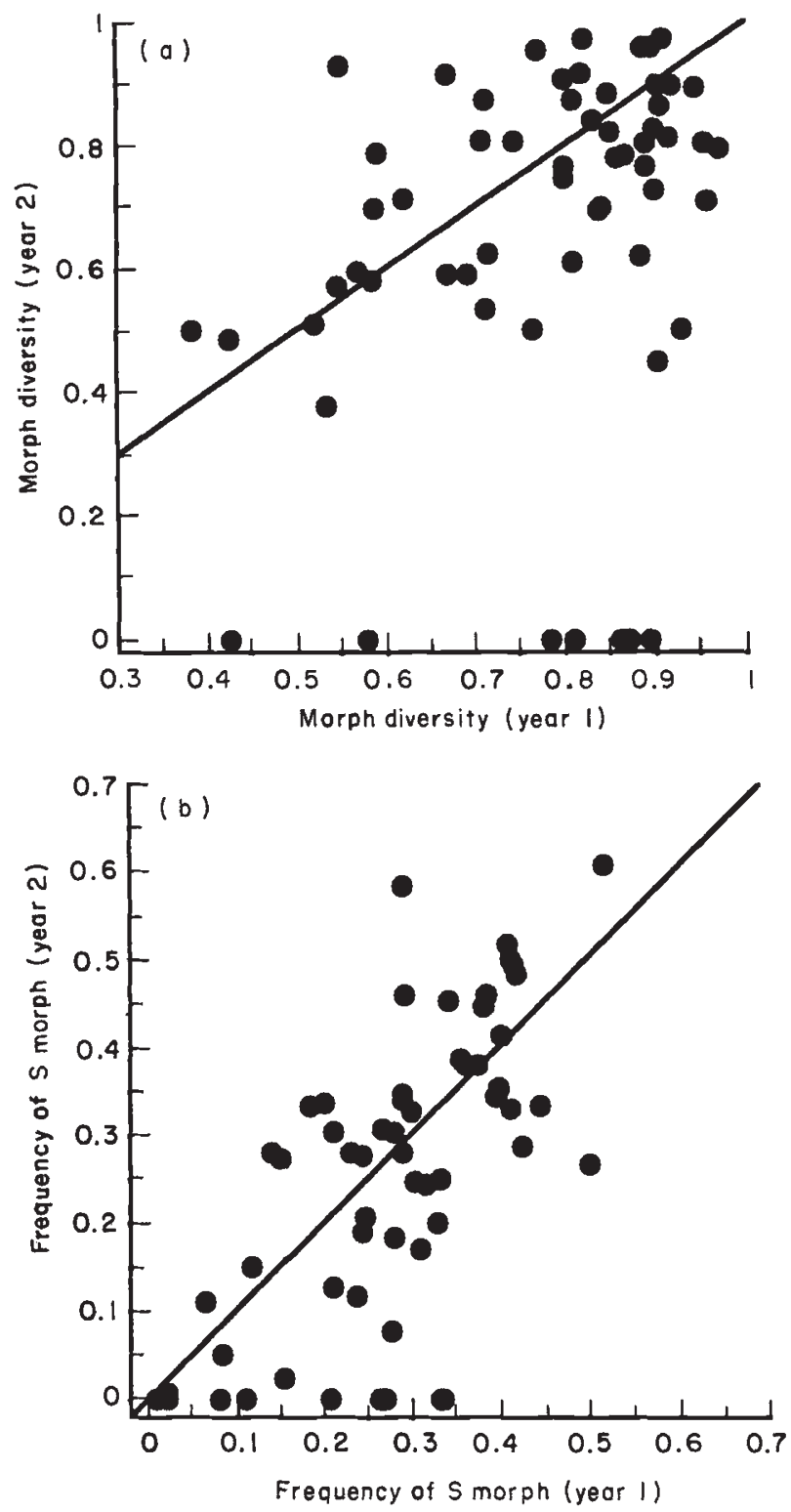

Fig. 3 Correlation between morph frequencies in 59 trimorphic populations of E. paniculata sampled in two consecutive years in northeastern Brazil. Morph frequency was represented by (a) morph diversity ( $O$ index) and (b) frequency of the $\mathrm{S}$ morph. Points located along the abscissa represent those populations that lost (a) two morphs $(n=7)$ and (b) the $\mathrm{S} \operatorname{morph}(n=11)$ after 2 consecutive years. The solid line represents a correlation of 1 .

Change in morph frequency and population size. The magnitude of morph frequency change ( $P$ index) was inversely proportional to population size. Temporal variation in morph diversity and the frequency of the $S$ morph in trimorphic populations in relation to population size are presented in Fig. 4a and b. For both variables, the mean change was significantly greater in small population size-classes than large size-classes
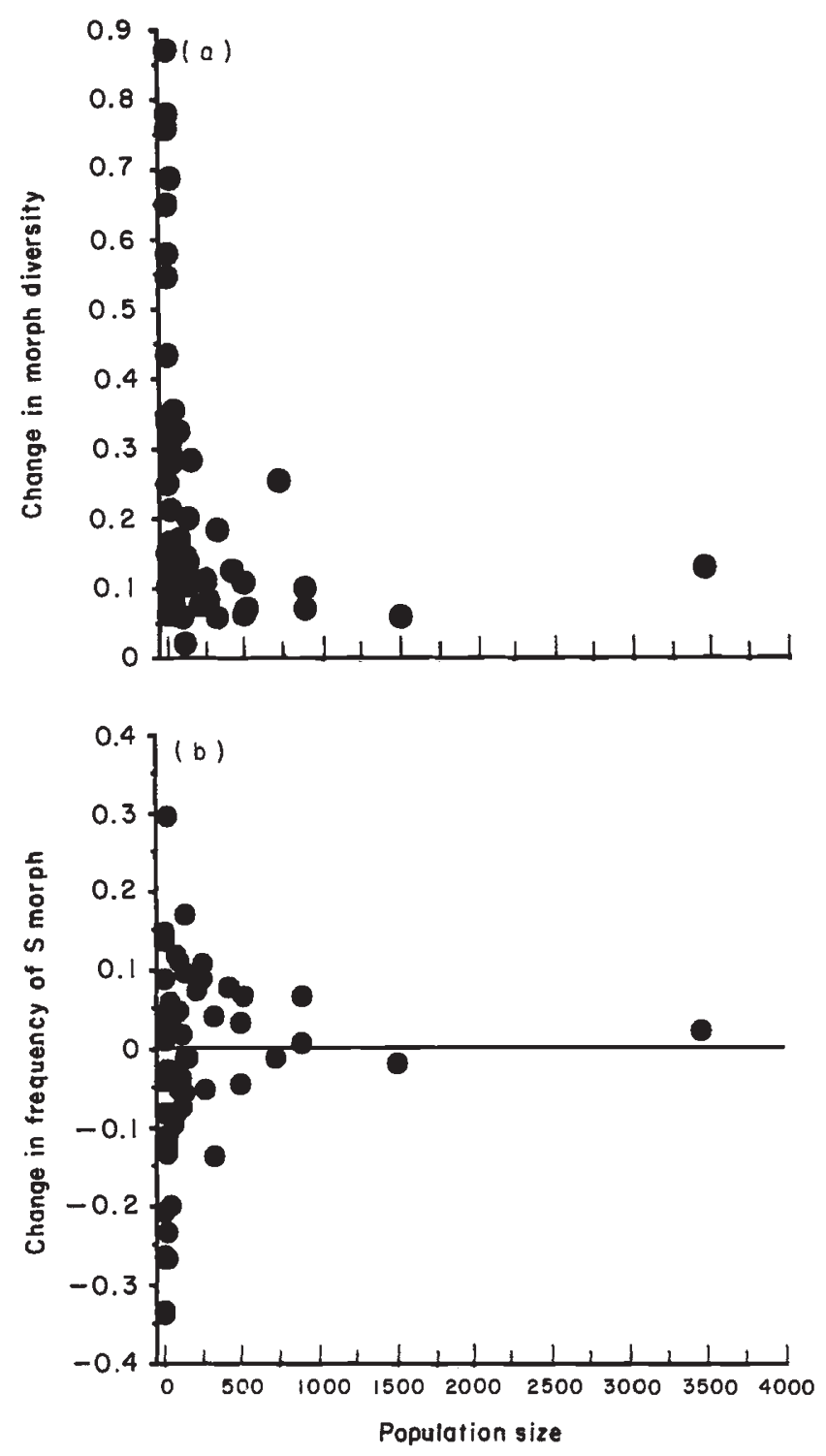

Fig. 4 Morph frequency variation as a function of population size in 59 trimorphic populations of $E$. paniculata from northeastern Brazil sampled over two consecutive years. Morph frequency was represented by (a) morph diversity index ( $P$ index $)$ and (b) the frequency of the $\mathrm{S}$ morph. Population size was the harmonic mean of all yearly censuses.

(Morph diversity; Kruskal-Wallis $H=14.51, P<0.01$, d.f. $=4$ : frequency of the $S$ morph: Kruskal-Wallis $H=13.8, p<0.01$, d.f. $=4$; Table 5). Whether morph frequencies became more or less even was statistically independent of the size-class to which a population belonged [Morph diversity ( $O$ index); $\chi^{2}=2.61$, $P>0.5$, d.f. $=4$ : frequency of $S$ morph; $\chi^{2}=3.03$, $p>0.5$, d.f. $=4]$.

The relationship between population size and changes in morph diversity was also evident in simulated populations of comparable size (Table 5). 
Table 5 Average change in morph diversity $(P$ index $)$ in trimorphic populations of $E$. paniculata surveyed for 2 consecutive years in northeastern Brazil. Theoretical means (SD) due entirely to stochastic forces were generated from Monte Carlo simulations of trimorphic populations, replicated 100 times. The number of populations in each simulation and their size correspond to the sample sizes $(n)$ and midpoints, respectively, of the observed size classes. A second set of theoretical predictions $\left(\right.$ Expected $_{\text {adj }}$ ) was generated, taking into account that effective population size is about 6.3 times less than size estimates in this study. Asterisks indicate a significant difference between observed and expected values based on a two-tailed $t$-test

\begin{tabular}{crlll}
\hline & \multicolumn{4}{c}{ Change in morph diversity } \\
\cline { 3 - 5 } Size class & $n$ & Observed & Expected & Expected $_{\text {adj }}$ \\
\hline $1-25$ & 19 & 0.40 & $0.19^{*} \pm 0.025$ & $0.34 \pm 0.046$ \\
$26-50$ & 10 & 0.17 & $0.10^{*} \pm 0.017$ & $0.26 \pm 0.048$ \\
$51-150$ & 14 & 0.13 & $0.07^{*} \pm 0.010$ & $0.17 \pm 0.022$ \\
$151-500$ & 8 & 0.13 & $0.04^{*} \pm 0.008$ & $0.10 \pm 0.016$ \\
$501-1500$ & 7 & 0.10 & $0.02^{*} \pm 0.007$ & $0.06^{*} \pm 0.013$ \\
\hline
\end{tabular}

Although the expected changes in morph frequency exhibited the same trend as the field observations, values from simulations were consistently less than field values for all size-classes. A second set of expected values was generated after the five population size-classes were adjusted to the genetically effective population size, which was about 6.3 times smaller. The expected changes in morph frequency were statistically similar to observed values in five of the six size-classes (Table 5).

\section{Discussion}

There is now considerable evidence that populations of Eichhornia paniculata throughout northeastern Brazil differ with respect to the frequency and number of mating types or floral morphs. In four annual surveys conducted during a 7-year period, between 22 and 44 per cent of populations were missing at least one morph. Empirical studies indicate that disassortative mating in E. paniculata is sufficiently strong to maintain style morphs at equal frequencies through frequency-dependent selection, provided populations are large (Barrett et al., 1987); however, less is known about the evolutionary forces leading to the loss of morphs from trimorphic populations, particularly those that are small in size.

In this study we found a significant relationship between morph structure and population size $\left(\chi^{2}=35.2, P<0.001\right)$. Large populations of E. paniculata tend to be trimorphic, while those that are dimorphic or monomorphic are usually small. This association has also been described for tristylous Lythrum salicaria (Eckert \& Barrett, 1992), which suggests that evolutionary processes in small populations can account for morph loss in tristylous species. Morph loss from trimorphic populations may result from genetic drift or through founder effects during colonization (Barrett, 1977; Barrett et al., 1989). The potential for both of these stochastic processes is likely to be strong in $E$. paniculata due to its patchy distribution, small effective population size and colonizing life history; however, more direct evidence is required to confirm that stochastic processes cause the loss of morphs from small tristylous populations. In this study, evidence from temporal patterns of morph frequency variation were used to evaluate the drift hypothesis.

Although the sampling interval over which populations were surveyed was relatively short, 20 per cent of populations censused for 2 consecutive years and 28 per cent censused for 3 years lost at least one style morph (Table 3). Moreover, the loss of morphs did not appear to occur with equal probability. Among the populations involved, the $\mathrm{S}$ morph was most likely to disappear while the $\mathrm{L}$ morph was least likely. This pattern is consistent with theoretical predictions of morph frequency dynamics in finite populations (Heuch, 1980; Barrett et al., 1989). The differential loss of morphs is due to the two-locus mode of inheritance of the style-length polymorphism (see Charlesworth, 1979) and the fact that the $S$ allele governing the short-styled phenotype is not carried by genotypes of the $\mathrm{L}$ and $\mathrm{M}$ morph.

The propensity to lose the $\mathrm{S}$ morph is consistent with the morph structure of E. paniculata populations in northeastern Brazil. Populations containing $\mathrm{L}$ and $\mathrm{M}$ morphs but missing the $\mathrm{S}$ morph were the only form of dimorphic population found in the first three surveys and the predominant form in all surveys (Table 2). The frequency with which style morphs were lost from individual populations of $E$. paniculata observed in consecutive years might lead to the expectation that few trimorphic populations should exist in northeastern Brazil. However, the results of surveys conducted over a 7-year period were remarkably constant, with approximately 70 per cent of populations remaining trimorphic (Table 2).

The observed difference between short- and longterm patterns of morph loss in E. paniculata may be a result of gene dispersal either in time or in space. Depending on the overlap in time of germination among seed cohorts from different years, seed banks may accentuate gene frequency variation in consecutive years but dampen the effects of drift over longer time periods (Waples, 1990). In E. paniculatä, a seed 
bank may cause populations that recently lost morphs to revert to a trimorphic structure in subsequent years. Evidence from experimental studies suggests that the duration of seed dormancy in E. paniculata may be limited because about 70 per cent of viable seed germinates within the first year (Husband, 1992); however, the consequences of this level of seed dormancy on style morph structure have not been fully investigated. The stable average morph structure, seen over a 7-year period on a broad geographical scale in $E$. paniculata, may also be explained by the movement of genes between populations. While individual populations may change markedly in morph structure over consecutive years, gene flow from neighbouring sources may act to restore morph number and thereby maintain populations in a drift-migration equilibrium. Local extinction and recolonization of populations may be a particularly important mechanism of gene movement in E. paniculata (Husband, 1992), which cannot be accounted for in short-term analyses of morph loss.

Stochastic processes are implicated not only in the pattern of morph loss from trimorphic populations but also in the magnitude of morph frequency variation within populations. Morph frequencies fluctuated markedly within trimorphic populations of $E$. paniculata, with about 32 per cent of populations examined for 2-3 years exhibiting significant changes. This is a substantially larger level of significance than the level expected by chance alone ( 5 per cent). However, these significance levels are not necessarily evidence for non-random forces because drift alone can lead to a high percentage of significant results. The probability of a significant result in finite populations is largely determined by the ratio of sample size $(S)$ to effective populations size $\left(N_{\mathrm{e}}\right)$ (Waples, 1989). If $S / N_{\mathrm{e}}$ is small, the probability of a significant test result is not much different than the nominal level ( 5 per cent), even after many generations of drift; however, if $S / N_{\mathrm{e}}$ is large, the probability of a significant change in morph frequency increases. In E. paniculata, effective population size is considerably less than the census number of individuals. Because most populations contain less than 100 individuals, it is often possible to sample the entire population, in which case sample size exceeds effective size. Simulations of $E$. paniculata populations indicated that under such a sampling scheme, the probability of a significant result through stochastic processes alone ranged from 30 to 50 per cent. Therefore, the observed percentage of tests with significant results is not inconsistent with patterns expected based on drift alone.

If stochastic processes have an important influence on style morph dynamics, morph frequencies should not only vary with time but should also change randomly in direction. Observed changes in morph frequency in $E$. paniculata populations were consistent with this expectation. The frequency of the $S$ morph increased or decreased with equal frequency among populations censused for 1- and 2-year intervals. Morph diversity, however, tended to shift away from equal frequencies more often than towards. This most likely reflects a statistical constraint on the direction of change, rather than a non-random force acting on morph frequencies because approximately 50 per cent of all populations in the sample were at equal morph frequencies to begin with. Moreover, many of the changes in morph diversity away from isoplethy were statistically insignificant. When only populations with significant changes in morph frequency were included in the analysis, only 25 per cent were initially isoplethic and morph diversity changed with no bias in either direction.

An additional result in support of the role of stochastic forces in finite populations was the relationship between the magnitude of change in morph frequency and effective population size. The mean temporal change in morph diversity observed in trimorphic populations and the variance among populations was contingent upon the size class to which populations belonged. Morph diversity changed by an average of 35 per cent of the maximum in populations containing between 1 and 25 individuals, but only about 9 per cent in populations larger than 500 individuals. These values are in accord with the results of simulations of drift in tristylous populations with comparable effective population sizes and approximately the same levels of sampling error.

Collectively, our results are consistent with the hypothesis that genetic drift plays a dominant role in influencing the relative frequency of style morphs in finite populations of $E$. paniculata in northeastern Brazil. This is not to say, however, that deterministic factors may not influence style morph frequencies in tristylous populations of $E$. paniculata. Earlier field studies indicated that the $S$ morph may experience reduced seedset in populations where long-tongued specialist bees are absent (Barrett et al., 1989). However, because selective pressures related to pollinator availability are likely to operate episodically (see Husband \& Barrett, 1992b), their consequences may be too irregular to be detected within the time interval used in this study. In forming his definition of genetic drift, Wright (1931) recognized that inconstant selection may also be an important component of stochastic variation. While selective forces of a more constant nature may also contribute to the existing patterns of morph structure in E. paniculata, the strong stochastic 
component to temporal variation in style morph frequencies suggests these forces may be small enough to be ignored in many trimorphic populations.

\section{Acknowledgements}

We thank William Cole, Jan Conn and Martin Morgan for field assistance, Christopher Eckert and Martin Morgan for valuable discussions. Research was funded by an operating grant to SCHB from the Natural Sciences and Engineering Research Council of Canada.

\section{References}

BARRETT, S. C. H. 1977. Tristyly in Eichhornia crassipes (Mart.) Solms (Water Hyacinth). Biotropica, 9, 230-238.

BARRETT, S. C. H. 1985a. Floral trimorphism and monomorphism in continental and island populations of Eichhornia paniculata (Spreng.) Solms (Pontederiaceae). Biol. J. Linn. Soc., 25, 41-60.

BARRETT, s. C. H. 1985b. Ecological genetics of breakdown in tristyly. In: Haeck, J. and Woldendorp, J. W. (eds) Structure and Functioning of Plant Populations, II. Phenotypic and Genotypic Variation in Plant Populations, North-Holland, Amsterdam. pp. 267-275.

BARRETT, S. C. H., BRoWN, A. H. D. AND SHORE, J. S. 1987. Disassortative mating in tristylous Eichhornia paniculata (Pontederiaceae). Heredity, 58, 49-55.

BARRETT, s. C. H. AND HUSBAND, B. C. 1990 . Variation in outcrossing rates in Eichhornia paniculata: the role of demographic and reproductive factors. Plant Sp. Biol., 5 , 41-55.

BARRETT, S. C. H. AND KOHN, J. R. 1991. Genetic and evolutionary consequences of small population size in plants: implications for conservation. In: Falk. D. A. and Holsinger, K. E. (eds) Genetics and Conservation of Rare Plants, Oxford University Press, New York. pp. 3-30.

BARRETT, s. C. H., MORGAN, M. T. AND HUSBAND, B. C. 1989. The dissolution of a complex genetic polymorphism: the evolution of self-fertilization in tristylous Eichhornia paniculata (Pontederiaceae). Evolution, 43, 1398-1416.

BILLINGTON, H. L. 1991. Effect of population size on genetic variation in a dioecious conifer. Con. Biol., 5, 115-119.

CHARLESWORTH, D. 1979. The evolution and breakdown of tristyly. Evolution, 33, 486-498.

ECKERT, C. G. AND BARRETT, S. C. H. 1992. Stochastic loss of style morphs from populations of tristylous Lythrum salicaria and Decodon verticillatus (Lythraceae) Evolution, (in press).

EPLING, C. AND DOBZHANSKY, T. 1942. Genetics of natural populations. VI. Microgeographical races in Linanthus parryae. Genetics, 27, 317-332.

FISHER, R. A. 1944. Allowance for double reduction in the calculation of genotype frequencies with polysomic inheritance. Ann. Eugen., 11, 31-38.

HANSKI, I. 1985. Colonization of ephemeral habitats. In: Pickett, S. T. A. and White, P. S. (eds) The Ecology of Natural Disturbance and Patch Dynamics, Academic
Press, NY. pp. 155-183.

HARRISON, S., MURRAY, D. D. AND EHRLICH, P. R. 1988. Distribution of the bay checkerspot butterfly, Euphydryas editha bayensis: evidence for a metapopulation model. Am. Nat., 360-382.

HEUCH. I. 1979. Equilibrium populations of heterostylous plants. Theor. Pop. Biol., 15, 43-57.

HEUCH, I. 1980. Loss of incompatibility types in finite populations of the heterostylous plant: Lythrum salicaria. Hereditas, 92, 53-57.

HEUCH, I. AND LIE, R. T. 1985. Genotype frequencies associated with incompatibility systems in tristylous plants. Theor. Pop. Biol., 27, 318-336.

HUSBAND, B. C. 1992. Stochastic processes and the evolution of self-fertilization in Eichhornia paniculata (Spreng.) Solms. (Pontederiaceae). PhD Thesis, University of Toronto, Toronto, Canada.

HUSBAND, B. C. AND BARRETT, s. C. H. 1992a. Effective population size and genetic drift in tristylous Eichhornia paniculata (Pontederiaceae). Evolution (in press).

HUSBAND, B. C. AND BARRETT, S. C. H. 1992b. Pollinator visitation to populations of tristylous Eichhornia paniculata (Pontederiaceae) in northeastern Brazil. Oecologia, 89, 365-371.

LANDE, R. AND BARROWCLOUGH, G. F. 1987. Effective population size, genetic variation and their use in population management. In: Soulé, M. E. (ed.) Viable Populations for Management, Cambridge University Press, Cambridge. pp. 87-124.

MCCLENAGHAN, L. R. JR. AND BEAUCHAMP, A. C. 1986. Low genic differentiation among isolated populations of the California fan palm (Washingtonia filifera). Evolution, 40, 315-322.

MORAN, G. F. AND HOPPER, S. D. 1983. Genetic diversity and the insular population structure of Eucalyptus caesia. Beuth. Aust. J. Bot., 31, 161-172.

MORGAN, M. T. AND BARRETT, S. C. H. 1988. Historical factors and anisoplethic population structure in tristylous Pontederia cordata: a reassessment. Evolution, 42, 496-504.

OLIVIERI, I., COUVET, D. AND GOUYON, P. 1990. The genetics of transient populations: research at the metapopulation level. Trends Ecol. Evol., 5, 207-210.

OXFORD, G. S. AND SHAW, M. w. 1986. Long-term variation in colour-morph frequencies in the spider Enoplognatha ovata (Clerk) (Araneae: Theridiidae): natural selection, migration and intermittent drift. Biol. J. Linn. Soc., 27, 225-249.

WAPLES, R. S. 1989. Temporal variation in allele frequencies: testing the right hypothesis. Evolution, 43, 1236-1251.

WAPLES, R. S. 1990. Conservation genetics of Pacific Salmon I. Temporal changes in allele frequency. Con. Biol., 4, 144-156.

WRIGHT, s. 1931. Evolution in Mendelian populations. Genetics, 16, 97-159.

WRIGHT, $\mathbf{s}$. 1938. Size of population and breeding structure in relation to evolution. Science, 87, 430-431.

WRIGHT, s. 1943. An analysis of local variability of flower color in Linanthus parryae, Genetics, 28, 139-156.

WRIGHT, s. 1951. The genetical structure of populations. Ann. Eugen., 15, 323-354. 